\title{
Estudo histológico, imuno-histoquímico e ultra-estrutural das lesões induzidas experimentalmente por Ramaria flavo- brunnescens (Clavariaceae) em bovinos ${ }^{1}$
}

\author{
Sandro V. Schons ${ }^{2}$, Glaucia D. Kommers ${ }^{3}$, Guisepe M. Pereira ${ }^{4}$, Margarida B. Raffi ${ }^{5}$ e \\ Ana Lucia Schild ${ }^{6 *}$
}

\begin{abstract}
Schons S.V., Kommers G.D., Pereira G.M., Raffi M.B. \& Schild A.L. 2007. [Microscopic, immunohistochemical, and ultra-structural study of the lesions experimentaly induced by Ramaria flavo-brunnescens (Clavariaceae) in cattle.] Estudo histológico, imunohistoquímico e ultra-estrutural das lesões induzidas experimentalmente por Ramaria flavobrunnescens (Clavariaceae) em bovinos. Pesquisa Veterinária Brasileira 27(7):269-276. Laboratório Regional de Diagnóstico, Universidade Federal de Pelotas, Campus Universitário s/n, Pelotas, RS 96010-900, Brazil. E-mail: alschild@terra.com.br

The objective of this study was to investigate the pathogenesis of the lesions observed in cattle experimentally poisoned by Ramaria flavo-brunnescens. The mushroom was given to three 9 to 10 -month-old Jersey calves immediately after harvesting. Daily doses were around $20 \mathrm{~g} / \mathrm{kg}$ of body weight during 7 (Calf 1 ) or 13 days (Calves 2-3), and the total doses of mushroom given were 140,268 , and $261 \mathrm{~g} / \mathrm{kg}$ of body weight, respectively. One calf (Calf 4 ) with same age and breed was used as control. Clinical signs were characterized by prostration, anorexia, hyperemia of oral mucosa, and loosening of long hairs of the tail tip under mild traction. The calves were submitted to euthanasia and necropsied on days 8 (Calf 1 ) and 15 (Calves 2-4) after the beginning of the experiment. Microscopically, there was smoothness of dorsal epithelium of tongue with absence of filiform papillae, vacuolation of keratinocytes, and loosening of the keratin layer. In the hooves, there was vacuolation and irregular keratinization of the laminar epidermis and hyperplasia of keratinocytes. Hyperkeratosis, vacuolation of the external root sheath, thickening of tricholemal keratin, and inflammatory infiltration around hair follicles were observed on the skin of the tail tip. Immunohistochemical results with anti-pancytoceratin and anti-Ki67 (cell proliferation marker) antibodies showed no differences between the tongue dorsal epithelium of the control and experimental calves. Ultrastructural study demonstrated decrease in tonofilaments and increased intercellular spaces of the spinous layer of the tongue dorsal epithelium. The results of this study favor the hypothesis of an interference with the epithelial keratinization mechanisms by the toxic principles of Ramaria flavo-brunnescens.
\end{abstract}

INDEX TERMS: Ramaria flavo-brunnecens, mushroom poisoning, cattle diseases, pathology.

\footnotetext{
${ }^{1}$ Recebido em 4 de dezembro de 2006.

Aceito para publicação em 20 de dezembro de 2006.

Parte da Dissertação de Mestrado do primeiro autor.

2 Pós-Graduando em Medicina Veterinária, área de concentração em Patologia Veterinária, Laboratório Regional de Diagnóstico, Universidade Federal de Pelotas (UFPel), Campus Universitário s/n, Pelotas, RS 96010-900.

${ }^{3}$ Laboratório de Patologia Veterinária, Departamento de Patologia, CCS, Universidade Federal de Santa Maria, 97105-900 Santa Maria, RS.

${ }^{4}$ Aluno de Graduação, bolsista PIBIC, Faculdade de Veterinária, UFPel.

${ }^{5}$ Departamento de Patologia, Faculdade de Veterinária, UFPel.

${ }^{6}$ Laboratório Regional de Diagnóstico, Faculdade de Veterinária, UFPel, *Autor para correspondência: alschild@terra.com.br
}

RESUMO.- O objetivo deste trabalho foi estudar a patogenia das lesões observadas em bovinos intoxicados experimentalmente por Ramaria flavo-brunnescens. O cogumelo foi administrado imediatamente após a coleta a três bovinos da raça Jersey com 9-10 meses de idade. A dose diária administrada foi cerca de $20 \mathrm{~g} / \mathrm{kg}$ de peso vivo durante 7 (Bovino 1) e 13 dias (Bovinos 2 e 3), perfazendo doses totais de 140, 268 e 261g/ $\mathrm{kg}$ de peso vivo a cada bovino, respectivamente. Um bovino (Bovino 4) da mesma raça e idade foi utilizado como controle. Os sinais clínicos observados nos bovinos intoxicados, caracterizaram-se por apatia, anorexia, hiperemia da mucosa 
oral, alisamento da superfície dorsal da língua e queda dos pêlos longos da cauda quando levemente tracionados. Os bovinos foram submetidos à eutanásia e necropsiados no $8^{\circ}$ (Bovino 1) e no $16^{\circ}$ dia (Bovinos 2-4) após o início do experimento. Histologicamente observou-se o epitélio da superfície dorsal da língua estreito com ausência das papilas filiformes, vacuolização dos queratinócitos e desprendimento da camada queratinizada. Na região laminar dos cascos observou-se vacuolização das lâminas epidérmicas, hiperplasia dos queratinócitos e queratinização irregular e flocular. Na pele da extremidade da cauda havia hiperqueratose ortoqueratótica, vacuolização da bainha radicular externa, espessamento da queratina triquilêmica e infiltrado inflamatório mononuclear ao redor dos folículos. No estudo imunohistoquímico, utilizando os anticorpos anti-pancitoqueratina e antiKi67 (para marcação da proliferação celular) não foram observadas diferenças entre o epitélio da superfície dorsal da língua dos bovinos intoxicados e o do bovino controle. No estudo por microscopia eletrônica, observou-se diminuição dos tonofilamentos e espaços intercelulares acentuadamente dilatados na camada espinhosa do epitélio da língua. Os resultados obtidos neste trabalho favorecem a hipótese de ação do princípio tóxico de Ramaria flavo-brunnescens sobre os mecanismos que envolvem a queratinização dos epitélios em bovinos.

TERMOS DE INDEXAÇÃO: Ramaria flavo-brunnescens, intoxicação por cogumelo, doença de bovinos, patologia.

\section{INTRODUÇÃO}

A intoxicação espontânea pelo cogumelo Ramaria flavobrunnescens (fam. Clavariaceae) foi descrita no Brasil em bovinos de diferentes idades e raças nos estados do Rio Grande do Sul e São Paulo, com morbidade variando de 10-100\% e mortalidade de 10-90\% (Bauer et al. 1966, Santos et al. 1975, Riet-Correa et al. 1983, Barros et al. 2006). A intoxicação em bovinos também foi descrita no Uruguai (Freitas et al. 1966) e na Argentina (Perusia \& Rodriguez-Armesto 1992).

Em ovinos, a intoxicação espontânea foi relatada no Rio Grande do Sul (Riet-Correa et al.1983), São Paulo (Prucoli \& Camargo 1966) e no Uruguai (Freitas et al. 1966). A taxa de morbidade nesta espécie pode ser de $50-60 \%$ e a mortalidade de 0-45\% (Quiñones-Sowerby 1973). Recentemente, a doença foi descrita em búfalos (Rozza et al. 2004) e em um eqüino (Barros 2005) no Rio Grande do Sul.

As alterações clínico-patológicas da intoxicação causada pelo cogumelo em bovinos incluem anorexia, sialorréia, depressão, alisamento da superfície dorsal da língua, ulcerações multifocais na língua e no esôfago, afrouxamento e perda dos pêlos da vassoura da cauda e da porção córnea dos cascos e chifres. Pode observar-se, também, opacidade da córnea e hemorragia da câmara anterior do olho (Santos et al. 1975, Kommers \& Santos 1995, Riet-Correa et al. 2004, Barros et al. 2006).

O estudo experimental das lesões que ocorrem na intoxicação pelo cogumelo R. flavo-brunnescens em bovinos demonstrou que as alterações macroscópicas e histológicas envol- vem mais acentuadamente as estruturas que sofrem queratinização dura (papilas filiformes linguais, pêlos longos da cauda, cascos e chifres), onde há alta percentagem de aminoácidos sulfurados, como a cistina (Kommers \& Santos 1995). Uma interferência no metabolismo da cistina por deficiência de enxofre, semelhantemente ao que foi proposto na intoxicação crônica por selênio em bovinos (O'Toole \& Raibeck 1995), resultaria no enfraquecimento da estrutura molecular da queratina dura, levando à queda dos cascos, dos pêlos da extremidade da cauda, dos chifres e ao desaparecimento das papilas filiformes linguais (Kommers \& Santos 1995). Barros et al. (2006), baseados no estudo de lesões observadas na intoxicação espontânea em bovinos, sugeriram que este provavelmente seja o principal mecanismo patogenético para as lesões observadas nesta espécie.

Por outro lado, Sallis et al. (1993) estudando a intoxicação experimental em ovinos, sugeriram que as lesões seriam provocadas por uma substância vasoconstritora presente no cogumelo, cuja estimulação persistente na musculatura lisa da túnica média das arteríolas, resultaria em espessamento da mesma (miopaquinse) e vasoconstrição, o que teria como conseqüência necrose coagulativa e ulceração do epitélio irrigado por esses vasos. Esse mecanismo seria semelhante ao que ocorre no ergotismo (Sallis et al. 1993).

Os estudos de casos espontâneos e experimentais da intoxicação por este cogumelo em bovinos publicados até o momento, exploraram os aspectos microscópicos das lesões através da coloração de rotina (hematoxilina-eosina). No presente estudo, utilizou-se também a técnica de imunoistoquímica, numa tentativa de esclarecer os mecanismos envolvidos no desenvolvimento das lesões epiteliais. Dois aspectos principais foram abordados: a imunomarcação de filamentos de citoqueratina, utilizada para tentar detectar alterações no padrão de imunomarcação que pudessem sugerir defeitos na queratinização, e a imunomarcação de queratinócitos em processo de proliferação celular no epitélio superficial da língua, através da qual objetivou-se verificar se havia redução na replicação dos queratinócitos, justificando assim a aparente atrofia epitelial observada. A patogenia das lesões da língua foi investigada, também, mediante a utilização da microscopia eletrônica.

\section{MATERIAL E MÉTODOS}

Para o experimento, utilizou-se cogumelo colhido diariamente em bosques de eucaliptos do município de Capão do Leão, RS, entre os meses de março e maio de 2004, o qual foi administrado aos bovinos experimentais imediatamente após a coleta. Quatro bovinos da raça Jersey (Bovinos 1-4), com 9-10 meses de idade, foram utilizados no experimento. Antes da administração, foram examinados os cascos, a língua e os pêlos longos da extremidade da cauda de cada animal experimental.

A dose diária do cogumelo, cerca de $20 \mathrm{~g} / \mathrm{kg}$ de peso vivo, foi triturada com água em liquidificador e administrada através de sonda oro-gástrica aos Bovinos 1-3, conforme o Quadro 1. Após a administração do cogumelo, os bovinos permaneceram em potreiro de campo nativo e receberam ração comercial para bovinos (1\% do peso corporal por dia) e água ad libitum. O Bovino 4 foi utilizado como controle, permanecendo no mesmo local e sob as mesmas condições que os 
animais experimentais. Os Bovinos 2 e 3 receberam o cogumelo durante 3 dias consecutivos, havendo um intervalo de 3 dias sem administração devido às intensas chuvas que ocorreram no período do experimento e que impediram a coleta diária do cogumelo. Após esses 3 dias foi reiniciada a administração completando-se 13 doses (Quadro 1).

Os bovinos intoxicados foram submetidos à eutanásia aos 8 (Bovino 1) e 16 (Bovinos 2 e 3) dias do início da administração do cogumelo (Quadro 1). O Bovino 4, utilizado como controle, também foi submetido à eutanásia aos 16 dias do início do experimento. Os quatro bovinos foram necropsiados e fragmentos de língua, extremidade da cauda, cascos e o encéfalo foram fixados em formalina tamponada a $10 \%$ por $48-72$ horas. Esses tecidos foram processados rotineiramente para o estudo histológico das lesões.

Amostras da língua dos quatro bovinos foram processadas para a realização da técnica de imunoistoquímica. Cortes histológicos de $3 \mu \mathrm{m}$ em lâminas silanizadas foram desparafinizados, hidratados e submetidos ao bloqueio da peroxidase endógena com peróxido de hidrogênio a 3\% por 20 minutos (min). A recuperação antigênica foi realizada em forno microondas com TRIS-EDTA em pH 9,0 por $10 \mathrm{~min}$ em potência máxima. O bloqueio de ligações inespecíficas foi realizado com leite em pó desnatado a $5 \%$ em PBS por 30min. A incubação com os anticorpos primários, diluídos em diluente de anticorpo (Antibody Diluent, DAKO Cytomation, Código S3022), foi realizada "overnight" em câmara úmida. Para a imunomarcação de citoqueratina, foi utilizado o anticorpo policlonal anti-pancitoqueratina bovina (DAKO Cytomation, Código Z0622, diluição 1:2000) e para marcação de proliferação celular foi utilizado o anticorpo

Quadro 1. Identificação e peso dos bovinos experimentais, quantidade total de Ramaria flavo-brunnescens administrada, dose total, número de administrações e dia da eutanásia

\begin{tabular}{cccccc}
\hline Bovino & Peso & $\begin{array}{c}\text { Total de cogumelo } \\
\text { administrado }(\mathrm{kg})\end{array}$ & $\begin{array}{c}\text { Dose total } \\
(\mathrm{g} / \mathrm{kg})\end{array}$ & $\begin{array}{c}\text { № de admi- } \\
\text { nistrações }\end{array}$ & Eutanásia \\
\hline 1 & $85 \mathrm{~kg}$ & 11,950 & 140 & 7 & $8^{\circ}$ dia \\
$2^{\text {a }}$ & $88 \mathrm{~kg}$ & 23,600 & 268 & 13 & $16^{\circ}$ dia \\
$3^{\text {a }}$ & $91 \mathrm{~kg}$ & 23,840 & 261 & 13 & $16^{\circ}$ dia \\
4 & $90 \mathrm{~kg}$ & - & - & - & $16^{\circ}$ dia
\end{tabular}

a Estes bovinos receberam o cogumelo durante 3 dias, suspendendo-se a administração por 3 dias e reiniciando a administração até completar 13 dias.

primário monoclonal anti-Ki67 (Biogenex, diluição 1:400). As seções foram incubadas com anticorpo secundário biotinilado (LSAB + KitPeroxidase, DAKO Cytomation, Código K0690) por 35min em temperatura ambiente. Seguiu-se a incubação com complexo estreptavidina-peroxidase (LSAB + Kit-Peroxidase, DAKO Cytomation, Código K0690) por 35min em temperatura ambiente. As lavagens entre as principais etapas foram realizadas com PBST (PBS + Tween 20) em pH 7,2. A revelação foi executada com DAB. As seções foram contracoradas com Hematoxilina de Harris por $1 \mathrm{~min}$, desidratadas e montadas em lamínulas com meio de montagem (Entellan, Merck). No estudo imunoistoquímico para marcação de proliferação celular utilizando-se o anticorpo anti-Ki67, a média de núcleos marcados positivamente na camada basal do epitélio da superfície dorsal da língua foi obtida através da contagem dos núcleos imunomarcados em 10 campos de maior aumento (400x) dividida por 10 .

Para o estudo ultra-estrutural, fragmentos da língua (porção craniodorsal) foram fixados em solução de glutaraldeído $2 \%$ e paraformaldeído $2 \%$ em tampão cacodilato de sódio, desidratados em uma série crescente de etanóis e incluídos em Epon. Os cortes semi-finos foram corados por azul de metileno. Em áreas selecionadas dos blocos foram feitos cortes ultra-finos contrastados por acetato de uranila e citrato de chumbo e observados em microscópio eletrônico de transmissão (Zeiss EM 109).

\section{RESULTADOS}

\section{Sinais clínicos}

Os principais sinais clínicos observados nos Bovinos 1-3 caracterizaram-se por apatia, anorexia, hiperemia da mucosa oral, alisamento da superfície dorsal da língua e queda dos pêlos longos da cauda, quando levemente tracionados. No Bovino 1, estes sinais foram observados entre quatro e seis dias após o início do experimento. Adicionalmente, observou-se sialorréia, secreção nasal serosa, emagrecimento acentuado. Sete dias após o início do experimento, este bovino apresentou dificuldades de manter-se em estação, permanecendo em decúbito lateral ou esternal por longos períodos, levantando-se somente quando forçado. Nos Bovinos 2 e 3, os sinais clínicos foram mais discretos incluindo alisamento da superfície dorsal da língua e queda dos pêlos da cauda sob leve tração, os quais foram observados entre quatro a seis dias após o início do experimento.
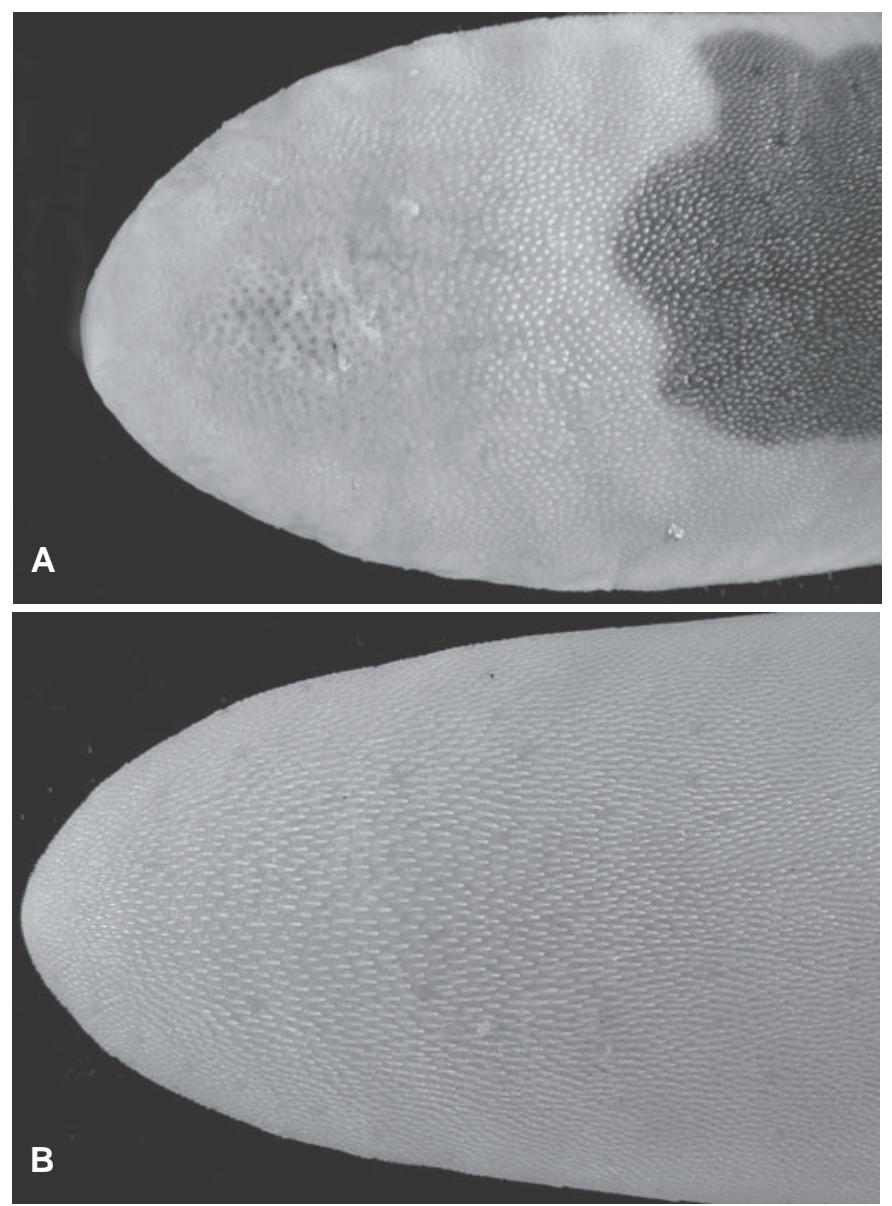

Fig.1. A) Na superfície dorsal do ápice da língua do Bovino 1, intoxicado por Ramaria flavo-brunnescens, observam-se atenuação das papilas filiformes, alisamento principalmente nos bordos laterais e presença de erosão na região central. B) Língua do Bovino 4 (Controle). 

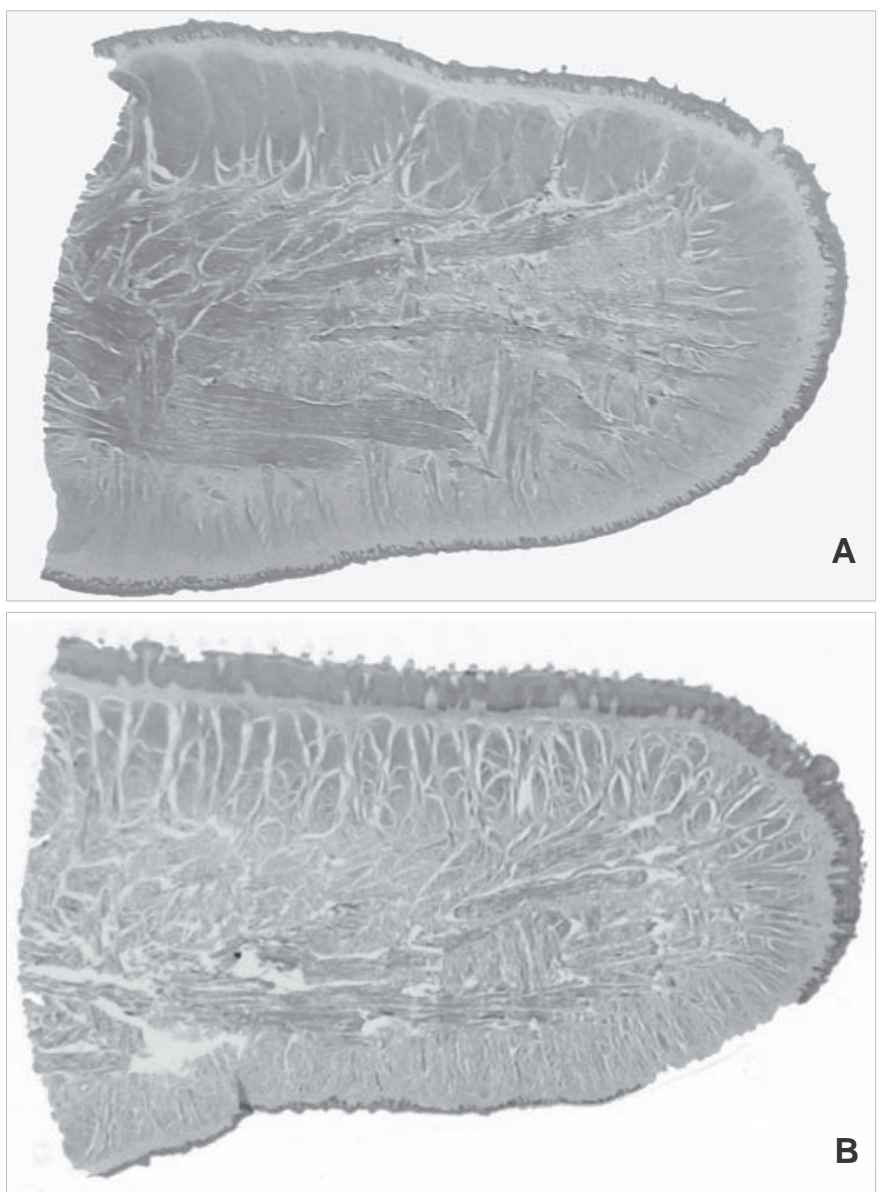

Fig.2. A) 0 epitélio da superfície dorsal da língua do Bovino 1, intoxicado por Ramaria flavo-brunnescens, está estreito e com atrofia das papilas filiformes. B) Na língua do Bovino 4 (Controle) são observadas numerosas papilas filiformes na superfície do epitélio dorsal o qual apresenta espessura normal. HE, submacroscópica.

\section{Patologia}

Macroscopicamente, observou-se atenuação das papilas filiformes e desaparecimento das papilas lentiformes da superfície dorsal da língua (Bovinos 1-3). No Bovino 1, havia também área de erosão no ápice da língua (Fig.1B). Não foram observadas alterações macroscópicas em outros órgãos ou tecidos nos Bovinos 1-4.

Histologicamente, no Bovino 1 observou-se o epitélio da superfície dorsal da língua estreito, com atrofia das papilas filiformes (Fig.2A e B). Havia, também, vacuolização dos queratinócitos e retenção de núcleos na camada superficial de queratina, que estava também vacuolizada. A vacuolização dos queratinócitos era observada principalmente na base das papilas filiformes (Fig.3A e B). Em algumas áreas havia, também, espongiose no estrato basal e disqueratose nas camadas superiores. Na lâmina própria adjacente ao epitélio havia discreto infiltrado inflamatório multifocal de células mononucleares. Nos Bovinos 2 e 3, observou-se que o epitélio da superfície dorsal da língua era mais estreito que o do bovino controle e que as papilas filiformes apresentavam o estrato córneo atenuado e sem a forma característica (semelhante à espinho de roseira).
As lesões histológicas observadas na região laminar do casco do Bovino 1 caracterizaram-se por vacuolização da epiderme laminar com hiperplasia de queratinócitos e queratinização irregular e flocular (Fig.4A e B). Nos Bovinos 2 e 3, as lesões eram mais discretas observando-se apenas vacuolização dos queratinócitos das lâminas epidérmicas.

Na pele da extremidade da cauda, somente no Bovino 1 observou-se hiperqueratose ortoqueratótica. Alguns folículos apresentavam vacuolização da bainha radicular externa e espessamento da queratina triquilêmica ao redor da haste do pêlo e infiltrado inflamatório mononuclear ao redor dos folículos. Não foram observadas alterações nos encéfalos dos bovinos intoxicados, nem nos tecidos examinados do bovino controle.

No estudo imunoistoquímico para marcação de proliferação celular utilizando-se o anticorpo anti-Ki67, não foram observadas diferenças entre o epitélio da superfície dorsal da língua do Bovino 1 e do Bovino 4 (Controle). A média de núcleos marcados positivamente para Ki67 no Bovino 1 foi de 47 e no controle foi de 46,7 (Fig.5A e B). Não foi possível estabelecer a média de núcleos imunomarcados para Ki67 nos Bovinos 2 e 3 devido à interferência de abundante quantida-
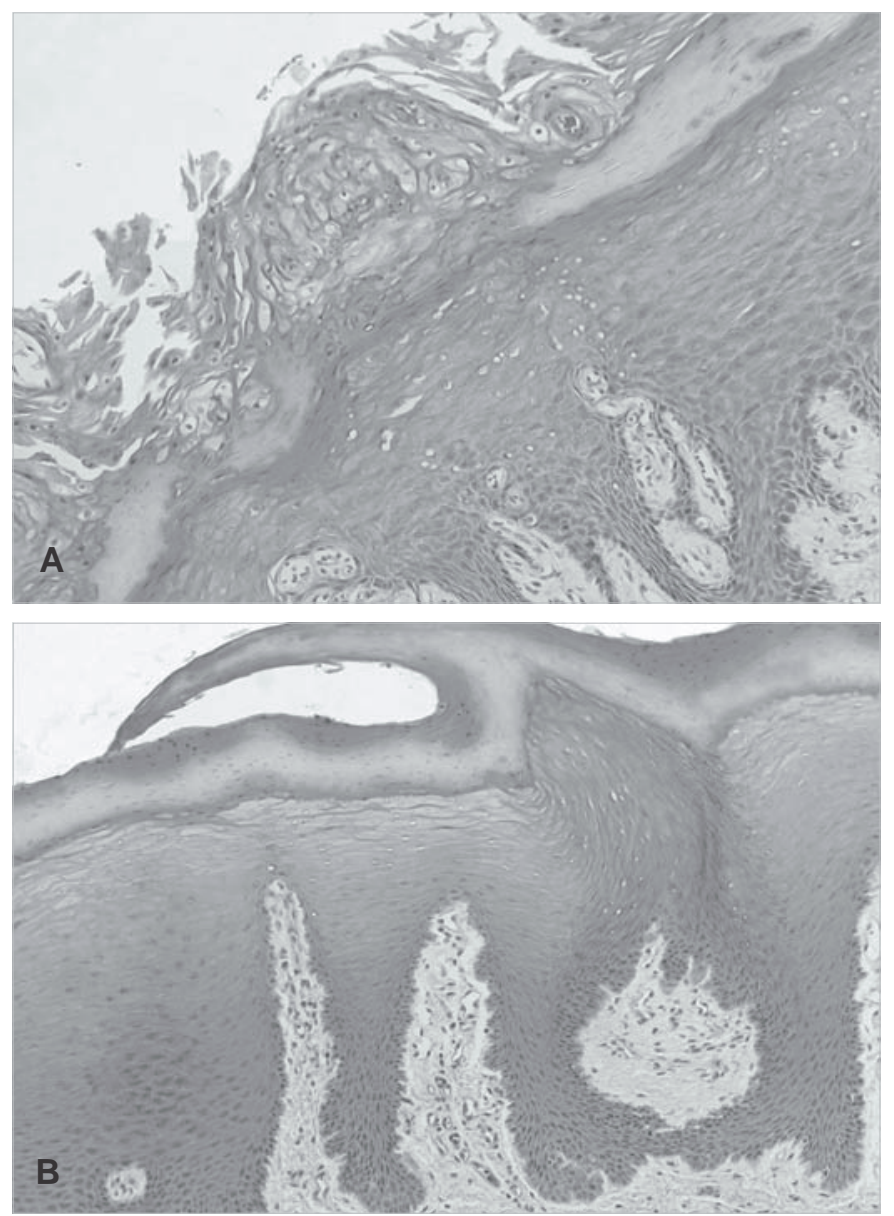

Fig.3. A). O epitélio da superfície dorsal da língua do Bovino 1 é estreito e há vacuolização dos queratinócitos na base das papilas filiformes atrofiadas e descamação da camada córnea. HE, obj.20. B) Epitélio da superfície dorsal da língua do Bovino 4 (Controle). HE, obj.10. 

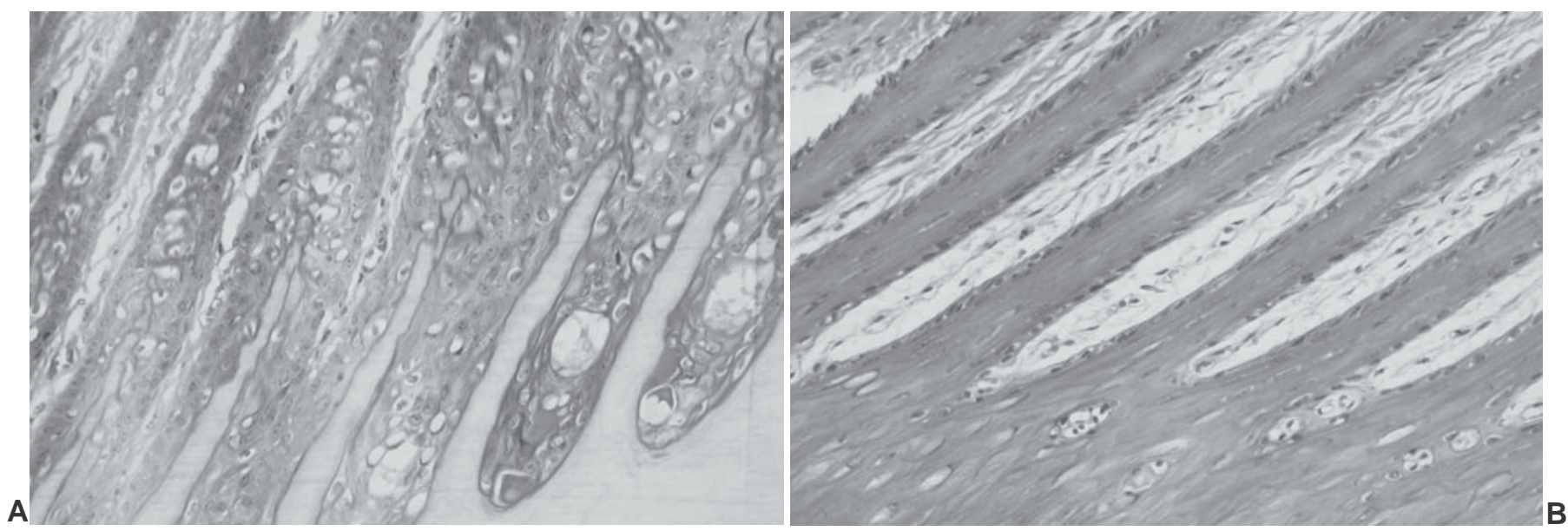

Figura 4. A) Na região laminar do casco do Bovino 1 há degeneração vacuolar dos queratinócitos das lâminas epidérmicas com queratinização irregular e flocular. B) Lâminas epidérmicas do casco do Bovino 4 (Controle). HE, obj.20.

de de melanina nos queratinócitos da camada basal do epitélio dorsal da língua nas seç̧ões examinadas. Utilizando-se o anticorpo anti-pancitoqueratina bovina, não foram observadas diferenças no padrão de imunomarcação entre o epitélio
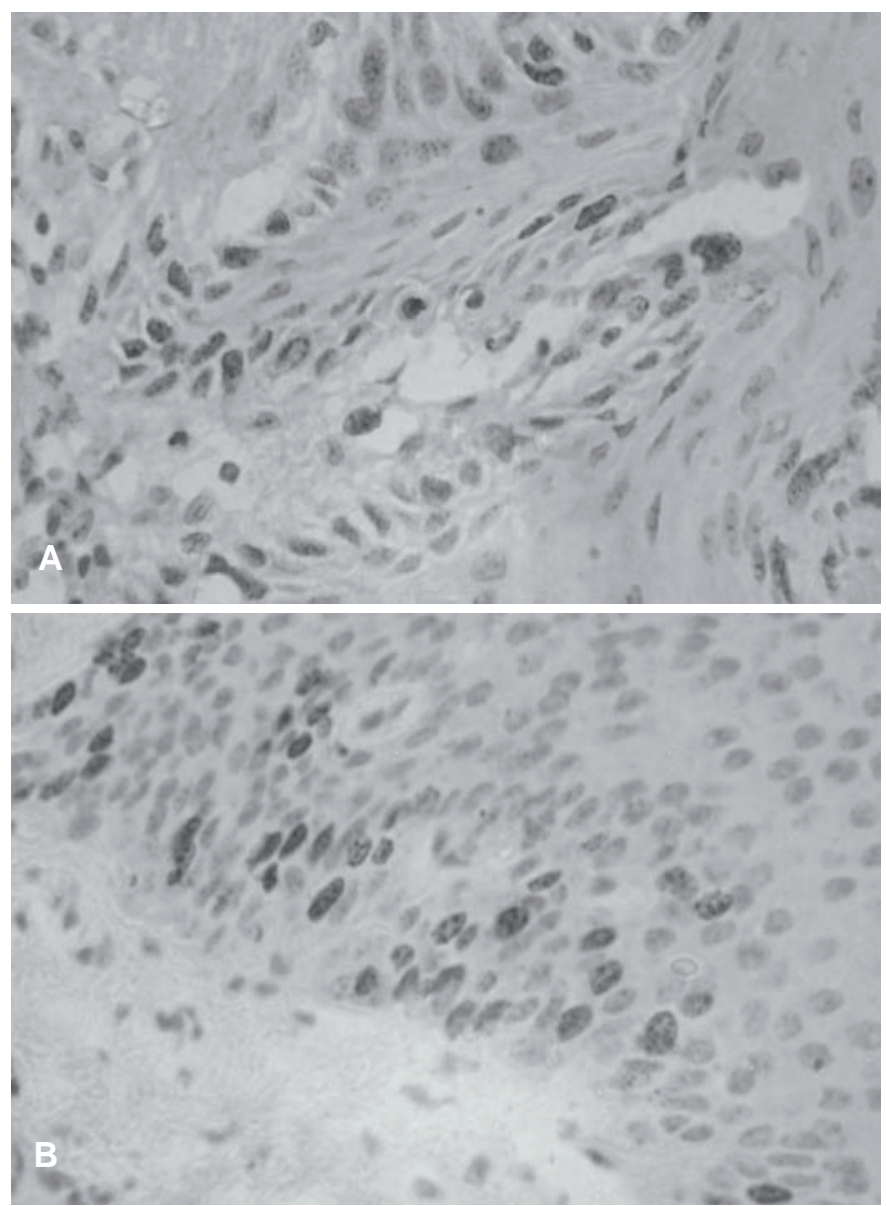

Fig.5. Imuno-histoquímica para marcação de proliferação celular com o anticorpo primário monoclonal anti-Ki67: não se observam diferenças de marcação celular entre o Bovino 1 intoxicado $(\mathrm{A})$ e o bovino controle (B). Obj.40. dorsal da língua dos bovinos intoxicados e do bovino controle.

No estudo da língua por microscopia eletrônica, observou-se que na camada espinhosa do epitélio superficial, os queratinócitos exibiam diminuição dos tonofilamentos (Fig.6A) quando comparados com os queratinócitos da mesma camada na língua do bovino controle (Fig.6B). Os desmossomos estavam bem conservados e os espaços intercelulares estavam acentuadamente dilatados (Fig.6A).

\section{DISCUSSÃO}

A investigação da patogenia das lesões observadas na intoxicação pelo cogumelo Ramaria flavo-brunnescens tem sido alvo de estudos experimentais em bovinos (Santos et al. 1975, Kommers \& Santos 1995) e em ovinos (Sallis et al. 1993). Tentativas de utilização de cobaios como modelo experimental não foram bem sucedidas, pois apesar de os cobaios serem suscetíveis à intoxicação, as lesões são somente de natureza inflamatória e diferem das lesões observadas em bovinos e ovinos (Raffi \& Schild 2000, dados não publicados). Isto justifica a utilização de bovinos para a reprodução experimental da intoxicação neste estudo. Adicionalmente, a disponibilidade de quantidades elevadas de cogumelo necessárias para provocar o quadro clínico e a necessidade de administrá-lo imediatamente após a coleta, explicam o número reduzido de unidades experimentais utilizadas neste trabalho.

Os resultados deste trabalho demonstraram que doses de cogumelo em torno de $140 \mathrm{~g} / \mathrm{kg}$ de peso vivo, administradas em doses fracionadas diárias de aproximadamente $20 \mathrm{~g} / \mathrm{kg}$ durante 7 dias, provocaram a intoxicação em bovinos. A partir do quarto dia do experimento, os bovinos já apresentavam sinais clínicos indicando que a dose total de $80 \mathrm{~g} / \mathrm{kg}$ de peso vivo foi suficiente para provocar as lesões iniciais. Em intoxicações experimentais realizadas anteriormente a dose mínima que causou sinais clínicos da intoxicação foi de $5 \mathrm{~g} / \mathrm{kg}$ de peso vivo durante cinco dias, perfazendo um total de $25 \mathrm{~g} /$ $\mathrm{kg}$ de peso vivo (Santos et al. 1975). Utilizando a mesma dose diária de cogumelo ( $20 \mathrm{~g} / \mathrm{kg}$ de peso vivo), outros autores ob- 

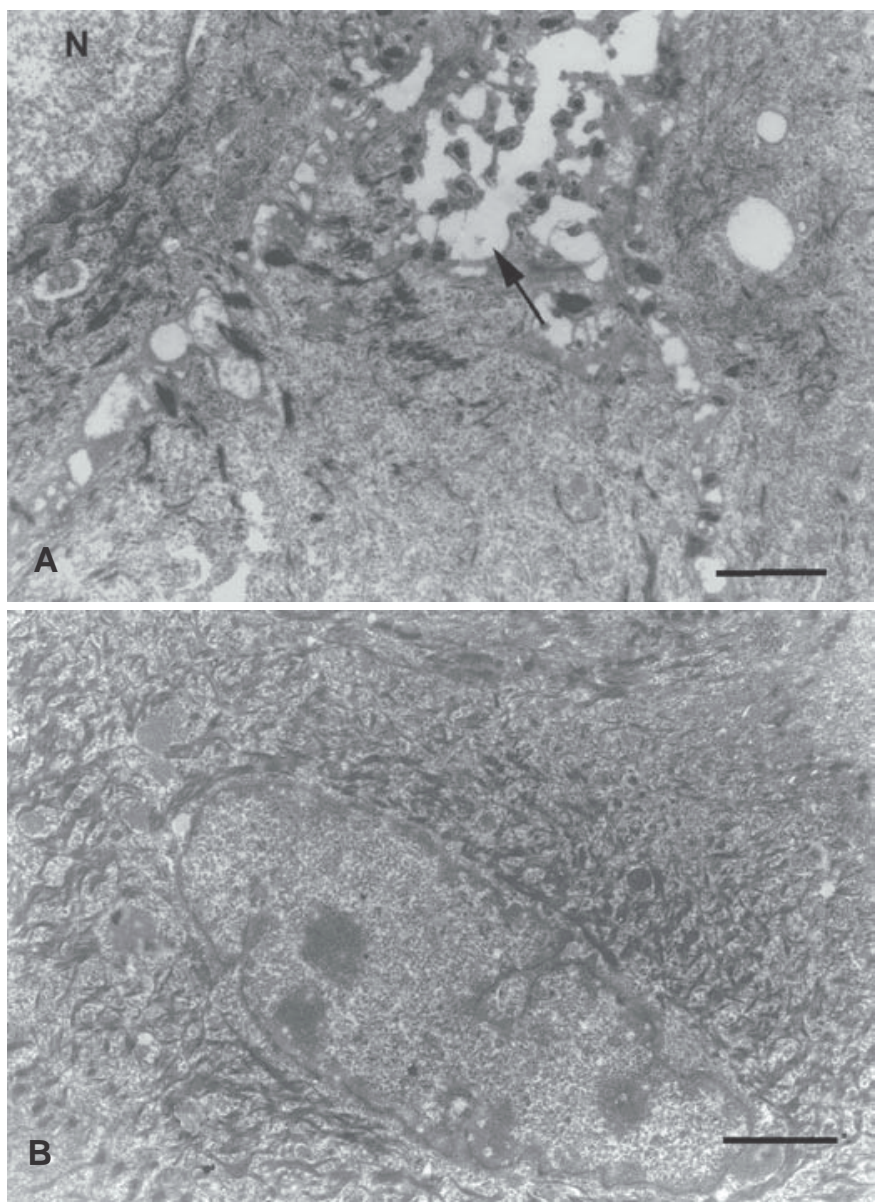

Fig.6. A) No bovino experimentalmente intoxicado com Ramaria flavobrunnescens, os queratinócitos da camada espinhosa do epitélio da língua, mostram diminuição dos tonofilamentos e dilatação dos espaços intercelulares (seta). $\mathrm{N}=$ núcleo. Barra $=2 \mu \mathrm{m}$. B) No Bovino 4 (Controle), os queratinócitos da camada espinhosa mostram padrão de distribuição normal dos tonofilamentos. Barra $=2 \mu \mathrm{m}$.

servaram o início dos sinais clínicos entre o terceiro e o sexto dias de experimento (Kommers \& Santos 1995). Estas diferenças são explicadas, provavelmente, pela variação na toxicidade do cogumelo, previamente demonstrada por Sallis et al. (2000), e também pela susceptibilidade individual dos animais ao princípio tóxico do mesmo.

Quanto à variação na toxicidade de $R$. flavo-brunnescens, chama a atenção que os Bovinos 2 e 3 apresentaram sinais clínicos e lesões macroscópicas e histológicas mais discretas que o Bovino 1, apesar de terem ingerido uma dose total maior do cogumelo em um período mais prolongado de tempo. Isto pode ser explicado pelo fato de que estes dois bovinos receberam o cogumelo colhido após um forte temporal que ocorreu durante 3 dias consecutivos no município de Capão do Leão, RS. Após esse período, observou-se que o cogumelo estava com coloração acastanhada ou amarelo-clara e amolecido, aparentando início de deterioração. Foi demonstrado anteriormente que o(s) princípio(s) tóxico(s) deste cogumelo apresenta(m) volatilidade e termolabilidade (Sallis et al. 1993, Kommers \& Santos 1995). No presente estudo, é provável que ele tenha reduzido sua toxicidade devido ao excesso de chuvas ocorrido no período do experimento com os Bovinos 2 e 3.

Neste trabalho, foram reproduzidas as alterações iniciais da intoxicação, caracterizadas principalmente por alisamento da superfície dorsal da língua e sinais de dor nos cascos, com consequiente decúbito prolongado. Observou-se também que através da tração leve era possível retirar os pêlos longos da cauda, embora não tenha sido observada a queda espontânea dos mesmos. Em casos naturais da intoxicação pelo cogumelo o alisamento da língua com atrofia das papilas filiformes é um achado constante (Barros 1958, Bauer et al. 1966, Freitas et al. 1966, Quiñones-Sowerby 1973, Santos et al. 1975, Paschoal et al. 1983, Riet-Correa et al. 1985, Schild et al. 1996, Barros et al. 2006). O adelgaçamento da superfície dorsal da língua foi acentuado no Bovino 1 (Fig.2) e observado, mais discretamente, nos Bovinos 2 e 3 deste estudo. Esta é, sem dúvida, a lesão inicial que ocorre na intoxicação por este cogumelo, manifestando-se associada à sialorréia abundante, descrita na maioria dos relatos da intoxicação espontânea e experimental em bovinos (Riet-Correa et al. 1985, Kommers \& Santos 1995, Schild et al. 1996, Barros et al. 2006).

As lesões histológicas observadas na língua do Bovino 1 (aos 8 dias de experimento), caracterizadas por vacuolização dos queratinócitos e desprendimento das camadas epiteliais queratinizadas, principalmente na base das papilas filiformes, não tinham sido descritas anteriormente. Em outros experimentos (Kommers \& Santos 1995), as lesões histológicas da língua foram examinadas após um período de tempo mais prolongado (mínimo de 12 dias), quando o epitélio dorsal da língua já se encontrava muito estreito e totalmente aplanado (mesma altura nas regiões papilares e interpapilares).

As papilas filiformes linguais parecem ser as primeiras estruturas afetadas pelo(s) princípio(s) tóxico(s) do cogumelo. Entretanto, as lesões estendem-se por todo o epitélio da superfície dorsal da língua, o que demonstra que o princípio tóxico tem um efeito sobre o epitélio queratinizado, envolvendo queratinócitos que sofrem queratinização mole (regiões interpapilares) e queratinização dura (papilas filiformes). Apesar de não terem sido observadas lesões no esôfago e préestômagos nos animais deste experimento, lesões ulcerativas no epitélio queratinizado destas regiões do trato alimentar têm sido descritas em casos espontâneos da intoxicação (Bauer et al. 1966, Quiñones-Sowerby 1973, Santos et al. 1975, Schild et al. 1996, Barros et al. 2006).

Nos cascos e na pele da cauda, as lesões microscópicas observadas (principalmente no Bovino 1) foram semelhantes às descritas experimentalmente (Kommers \& Santos 1995) e em casos naturais da intoxicação por $R$. flavo-brunescens em bovinos (Barros et al. 2006). As lesões observadas na região laminar do casco do Bovino 1, caracterizaram-se por vacuolização de queratinócitos e queratinização dura defeituosa, semelhantemente ao descrito por Kommers \& Santos (1995).

Utilizando o anticorpo anti-pancitoqueratina bovina (de- 
tectando citoqueratinas com diferentes pesos moleculares) não houve diferença no padrão de imunomarcação entre o epitélio dorsal da língua dos bovinos intoxicados e do bovino controle. Entretanto, deve-se considerar que há aproximadamente 20 tipos diferentes de citoqueratinas epiteliais (Pinkus et al. 1985, Dabbs 2006,) e que em humanos foi demonstrado que as diferentes regiões do epitélio da língua apresentam distintos padrões de expressão das citoqueratinas (Manabe et al. 1999). Estudos com marcadores de citoqueratina tipoespecíficos poderão trazer informações adicionais no estabelecimento da patogenia dos distúrbios na queratinização da língua causados por $R$. flavo-brunnescens.

Com a utilização do anticorpo anti-Ki67, não foram observadas diferenças no número de queratinócitos imunomarcados na camada basal do epitélio da superfície dorsal da língua entre o Bovino 1 e o bovino controle. Devido ao número reduzido de animais experimentais há necessidade de estudos adicionais, tanto em lesões da língua de casos espontâneos como experimentais, utilizando-se marcadores de proliferação celular como o Ki67, considerando que este anticorpo detecta uma proteína presente em todas as fases do ciclo celular, tendo uma relação direta com a fração de crescimento de uma população de células (Alves et al. 1999). Com essa técnica seria possível determinar se a marcada diminuição no número de camadas de queratinócitos do epitélio da língua descrita por Kommers \& Santos (1995) se deve a uma interferência na divisão celular na camada basal do epitélio da língua ou se estaria associada com um marcado desgaste do epitélio relacionado às alterações degenerativas observadas no epitélio dorsal da língua do Bovino 1 deste estudo.

Os resultados obtidos na microscopia eletrônica sugerem que o princípio tóxico deste cogumelo atuaria principalmente sobre o processo de queratinização, envolvendo os tonofilamentos dos queratinócitos da camada espinhosa, que estão diminuídos em relação aos tonofilamentos presentes nos queratinócitos do bovino controle. Esta diminuição poderia contribuir para o aumento dos espaços intercelulares observados, facilitando a diminuição da adesão entre as células cornificadas e posterior desprendimento das mesmas. Lesões similares observadas na microscopia eletrônica foram relatadas em bovinos intoxicados espontaneamente (Barros, 2005).

O processo de queratinização normal envolve um suprimento balanceado de nutrientes como aminoácidos, especialmente os que contêm enxofre, ácidos graxos, minerais, elementos traço como zinco e vitaminas como a biotina (Mülling et al. 1999). Em um estudo das estruturas do casco de bovinos sob condições de deficiências nutricionais foi observado que, além da importância dos aminoácidos ricos em enxofre na formação da queratina dura, a deficiência de biotina causou alterações qualitativas e quantitativas na síntese dos filamentos de queratina (Tomlinson et al. 2004). Foi sugerido que o princípio ativo do cogumelo interferiria no metabolismo dos aminoácidos sulfurados resultando no enfraquecimento da estrutura molecular principalmente da queratina dura (a qual contem mais cistina e ligações dissulfeto que a queratina mole) por deficiência de enxofre, levando à queda dos cascos, dos pêlos da extremidade da cauda, dos chifres e ao desaparecimento das papilas filiformes linguais (Kommers \& Santos 1995).

Os resultados obtidos neste trabalho estão mais de acordo com a hipótese de ação do(s) princípio(s) tóxico(s) de $R$. flavo-brunnescens sobre os mecanismos que envolvem a queratinização dos epitélios em bovinos, considerando que nos bovinos deste experimento não foram observadas lesões vasculares associadas à trombose e necrose isquêmica de extremidades (similares ao ergotismo) como as descritas experimentalmente em ovinos Sallis et al. (2000) e em um surto em bubalinos (Rozza et al. 2004).

Agradecimentos.- Ao Prof. Severo Sales de Barros pela realização e interpretação da microscopia eletrônica e à Embrapa-CPACT, pela doação dos bezerros experimentais.

\section{REFERÊNCIAS}

Alves V.A.F., Bacchi C.E. \& Vassallo J. 1999. Manual de imuno-histoquímica. Soc. Bras. Patol., São Paulo. 270p.

Barros S.S. 1958. Da possível incidência da toxicose pelo selênio em bovinos no Rio Grande do Sul. Dipan, Porto Alegre, 11:10-13.

Barros R.R. 2005. Intoxicação por Ramaria flavo-brunnescens (Clavariaceae). Dissertação de Mestrado, Universidade Federal de Santa Maria, Santa Maria, RS. 53p.

Barros R.R., Irigoyen L.F., Kommers G.D., Rech R.R., Fighera R.A. \& Barros C.S.L. 2006. Intoxicação por Ramaria flavo-brunnescens (Clavariaceae) em bovinos. Pesq. Vet. Bras. 26:87-96.

Bauer A.G., Laranja R.J. \& Santos A.G. 1966. Sobre a etiologia do chamado "mal do eucalipto". Arq. Inst. Pesq. Vet. Desidério Finamor, Porto Alegre, 3:85-90.

Dabbs D.J. 2006. Diagnostic immunohistochemistry. $2^{\text {nd }}$ ed. Churchill Livingstone - Elsevier, China, p.183-184.

Freitas J., Pasturino C.L., Quiñones-Sowerby C.A., Bellagamba C., Giambruno E., Infantozzi J.M., Decia J.C. \& Gerveñanzky W. 1966. Comunicación sobre una enfermedad aparecida em ganados del Uruguay em los últimos años (BOCOPA). 5 Congr. Panam. Med. Vet. Zootec., Caracas, p.152-159.

Kommers G.D. \& Santos M.N. 1995. Experimental poisoning of cattle by the mushroom Ramaria flavo-brunnescens (Clavariaceae): a study of the morphology and pathogenesis of lesions in hooves, tail, horns and tongue. Vet. Human Toxicol. 37:297-302.

Manabe M., Lim W.H., Winzer M. \& Loomis C.A. 1999. Architectural organization of filiform papillae in normal and black hairy tongue epithelium: Dissection of differentiation pathaways in a complex human epithelium according to their patterns of keratin expression. Arch. Dermatol. 135:177-180.

Mülling K.W., Bragulla H.H., Reese S., Budras D., Steinberg W. 1999. How structures in bovine hoof epidermis are influenced by nutritional factors. Anal. Histol. Embryol. 28:103-108.

O’Toole D. \& Raisbeck M. F. 1995. Pathology of experimentally induced chronic selenosis (alkali disease) in yearling cattle. J. Vet. Diagn. Invest. 7:364-373.

Paschoal J.P., Portugal M.A.S.C. \& Nazário W. 1983. Ocorrência do "mal do eucalipto” em bovinos no estado de São Paulo. Biológico 49:15-18.

Perusia O.R., Rodriguez-Armesto R. 1992. Plantas Tóxicas y Micotoxinas. Esperanza, Santa Fe, Argentina. 94p.

Pinkus G.S., Connor E.M., Etheridge C.L. \& Corson J.N. 1985. Optimal immunoreactivity of keratin proteins in formalin-fixed, paraffin embedded tissue requires preliminary trypsinization: An immunoperoxidase study of various tumors using polyclonal and monoclonal antibodies. J. Histochem. Cytochem. 33:465-473.

Prucoli J.O. \& Camargo W.V.A. 1966. Intoxicação experimental em ovinos com Clavaria spp. Bolm Industrial Animal, Nova Odessa, 23:177-178. 
Quiñones-Sowerby C.A. 1973. BOCOPA. Bolsa del libro de la Faculdade de Veterinaria Alberto Lasplaces, Montevideo, p.1-13.

Riet-Correa F., Schild A.L., Mendez M.C., Oliveira J.A., Gil-Turnes C. \& Gonçalves A. 1983. Intoxicação por Ramaria flavo-brunnescens (fungo do eucalipto). Laboratório Regional de Diagnóstico: Relatório de atividades e doenças de área de influência no período 1978/1982. Editora da Universidade, Pelotas. 54p.

Riet-Correa F., Schild A.L., Méndez M.C., Brod C.S. \& Ferreira J.L.M. 1985. Intoxicação por Ramaria flavo-brunnescens em bovinos. Laboratório Regional de Diagnóstico: doenças diagnosticadas no ano 1984. Editora Universitária, Pelotas, p.28-29.

Riet-Correa F., Barros C.S.L. \& Schild A.L. 2004. Intoxication by Ramaria flavobrunnescens in domestic animals, p.488-493. In: Acamovic T., Stewart C.S. \& Pennycott T.W. (ed.), Poisonous Plants and Related Toxins. CAB International, UK.

Rozza D.B., Spagnol C., Silva E.B., Callado A.K.C., Oliveira E.C. \& Driemeier D.
2004. Intoxicação por Ramaria flavo-brunnescens em búfalos. Pesq. Vet. Bras. 24(Supl.):56-57.

Sallis E.S., Riet-Correa F. \& Méndez M.C. 1993. Experimental intoxication by Ramaria flavo-brunnescens in sheep. N.Z. Vet. J. 41:224.

Sallis E.S.V., Riet-Correa F., Raffi M.B. \& Méndez M.C. 2000. Experimental intoxication by the mushroom Ramaria flavo-brunnescens in sheep. Vet. Human Toxicol. 42:321-324.

Santos M.N., Barros S.S. \& Barros C.S.L. 1975. Intoxicação em bovinos pelo cogumelo Ramaria flavo-brunnescens. Pesq. Agropec. Bras. 10:105-109.

Schild A.L., Riet-Correa F., Ruas J.L., Riet-Correa G., Fernandes C.G., Motta A., Méndez M.C. \& Soares M. 1996. Intoxicação por Ramaria flavo-brunnescens em bovinos. Bolm Laboratório Regional de Diagnóstico, Pelotas, 16:25-28.

Tomlinson D.J., Mülling C.H. \& Fakler T.M. 2004. Invited review: formation of keratins in the bovine claw: roles of hormones, minerals, and vitamins in functional claw integrity. J. Dairy Sci. 87:797-809. 